\title{
El Seminario Mayor, una comunidad eclesial educativa
}

\author{
ANDRÉS GaRcía DE LA CuERDA \\ RECTOR dEL SEMINARIO MAYOR DE MADRID
}

DOI: https://doi.org/10.52039/seminarios.v54i189-190.527

\section{INTRODUCCIÓN}

Deseo comenzar esta intervención agradeciendo muy cordialmente a la dirección de la Hermandad de Sacerdotes Operarios, y al Pontificio Colegio Español de San José, la oportunidad que me han brindado de poder intervenir en este Simposio con la siguiente comunicación sobre el Seminario Mayor como comunidad eclesial educativa. La acción de gracias a Dios por la celebración del centenario de Mosén Sol, el santo apóstol de las vocaciones, nos ofrece el marco providencial para evocar y también agradecer al Señor la publicación de la Exhortación Apostólica Pastores dabo vobis del Papa Juan Pablo II que, a mi juicio, tan grandes servicios viene prestando a la formación de los sacerdotes y de los que se preparan para serlo. En esta intervención me voy a permitir señalar algunas enseñanzas de las que nos brinda PDV sobre el Seminario Mayor - las notas que considero más significativas en este momento - no sólo con unas glosas teóricas más o menos acertadas, sino con el aderezo experimental de su aplicación en la formación sacerdotal.

Es inevitable que esta comunicación tenga un cierto carácter testimonial: las siguientes reflexiones y certezas pedagógicas se entretejen en la urdimbre de mi servicio como Rector al Seminario de Madrid. Un Seminario sereno y sosegado, relativamente numeroso, plural por las diferentes procedencias y biografías de los seminaristas, e inserto en la complejidad pastoral y social de una gran ciudad. Sin embargo, estoy 
seguro de que, más allá de estas circunstancias peculiares, las cuestiones de fondo resultarán familiares.

$1^{a}$ Nota.- Instituyó Doce, para que estuvieran con Él,... (Mc 3, 14). El Seminario: una comunidad apostólica en torno a Jesús

Estoy persuadido de que una de las enseñanzas más fecundas de PDV es la referida a la naturaleza del Seminario Mayor ${ }^{1}$. El Seminario Mayor es sobre todo, una comunidad educativa en camino: la comunidad promovida por el Obispo para ofrecer a quien es llamado por el Señor para el servicio apostólico, la posibilidad de revivir la experiencia formativa que el Señor dedicó a los Doce (PDV, 60 b). Ciertamente, esta imagen tan dinámica y sugerente hace relación, en primer lugar, a la analogía del Seminario con la primera comunidad apostólica convocada y reunida en torno al Señor. Ser a su manera una continuación en la Iglesia de la íntima comunidad apostólica formada en torno a Jesús (PDV, 60 c) es su identidad más profunda.

Los seminaristas, como los Doce Apóstoles, han escuchado de los labios del Señor una palabra llena de autoridad y de afecto: Venid conmigo, $y$ os haré llegar a ser pescadores de hombres. (Mc 1,17). Una palabra que les implica en la totalidad de su existencia y les cambia la vida. Una palabra que reclama del llamado la confianza plena y la entrega total: la obediencia de la fe, vivida en un proceso creciente de conversión, de comunión y de configuración con Cristo.

Pero, ante todo, esta palabra establece una relación nueva e inefable entre el amor de Dios que llama y la libertad del hombre que responde... (PDV, 36 a) con cada uno de los seminaristas. Dicho de otra forma, la llamada de Jesús al seguimiento es la manifestación del misterio ${ }^{2}$ de una existencia elegida por Dios desde antes de la creación del mundo (Ef 1,4) y convocada en un momento de su historia concreta para configurarse

${ }^{1}$ Así la recoge el Plan de Formación Sacerdotal para los Seminarios Mayores de la Conferencia Episcopal Española, nº 9 (PFS).

2 PDV 38 a: Ciertamente la vocación es un misterio inescrutable que implica la relación que Dios establece con el hombre, como ser único e irrepetible, un misterio percibido y sentido como una llamada que espera una respuesta en lo profundo de la conciencia, esto es, en aquel "sagrario del hombre, en el que éste se siente a solas con Dios, cuya voz resuena en la propia intimidad. 


\section{COMUNICACIÓN \\ El Seminario Mayor, una comunidad eclesial educativa}

sacramentalmente con el misterio de Cristo como Señor y Siervo, Sumo Sacerdote y Apóstol del Padre. Al Seminario le corresponde acompañar este proceso iniciático por el que el futuro sacerdote va siendo conducido e introducido espiritualmente en el misterio del que participará por el sacramento del Orden. Desde esta perspectiva mistérica podemos hablar de mistagogía 3 : el Seminario puede ser considerado como una gran catequesis mistagógica, y los formadores como verdaderos mistagogos, que con temor reverencial al misterio que es cada futuro sacerdote, le acompañan y le orientan, le corrigen y le ayudan a discernir la obra buena que Dios ha comenzado en él.

Ningún proyecto de formación sacerdotal debe ignorar, y menos sofocar, el misterio que envuelve toda vocación sacerdotal. Por ello, el Seminario debe ser entendido, ante todo, como una experiencia espiritual, suscitada, guiada, y alimentada por el Espíritu Santo, que es el Protagonista por antonomasia (PDV, 69 b) de la formación sacerdotal, cuya finalidad apunta a la recepción del Sacramento del Orden. He aquí la tonalidad mistérica que debe resonar en todo el proceso de la formación y la clave que debe dar unidad al conjunto. Certeramente lo sintetiza PDV, 42 c: ...vivir en el seminario, escuela del Evangelio, es vivir en el seguimiento de Cristo como los apóstoles; es dejarse educar por Él para el servicio del Padre y de los hombres, bajo la conducción del Espíritu Santo.

Dejarse educar por Cristo en el Espíritu Santo supone poner al Señor en el centro de toda la organización y tarea educativas del Seminario como lo único necesario según enseña Jesús a Marta (Lc 10, 42), programando con toda claridad el tiempo de cada día y de todos los días para estar con Él en la intimidad de la oración, para poder experimentar el ser amado por Él de forma totalmente personal, sin otra dedicación, actividad o inquietud por importante que sea. Nuestros seminaristas deben convencerse de que la vida cristiana, y más aún, la sacerdotal, no se sostienen si uno no se siente alcanzado por el amor de Jesucristo hasta las zonas más profundas del propio ser, experimentando su amistad y su consuelo, el perdón y la esperanza, su confianza en nuestra persona, el ánimo renovado para volver a la brega pastoral, para mantener la fidelidad a los compromisos sacerdotales... Formarse para el sacerdocio es aprender a dar una respuesta personal a la pregunta fundamental de Cristo: ¿Me amas? (Jn 21, 15). Para el futuro sacerdote, la respuesta no puede ser

3 En la Instrucción sobre la formación litúrgica en los Seminarios de la Congregación para la Educación Católica, del 3 de Junio de 1979, se habla de la formación mistagógica de los seminaristas entendiendo como tal que sean conducidos a través de la docencia y por la práctica celebrativa a una más profunda sintonía con el Misterio de Cristo. 
sino el don total de su vida (PDV, $42 \mathrm{c}$ ). El contenido de la respuesta no es otro que el crecer, cada día y todos los días, en la forma de vida de Cristo, Sacerdote y Pastor, recorriendo el camino de la santidad sacerdotal ${ }^{4}$. El Papa Benedicto XVI sintetiza la respuesta en aceptar la invitación de Cristo a seguirlo, a dejar todo atrás, y a dedicar su vida a buscar la santidad y a servir a su pueblo5.

El Seminario debe cuidar prioritariamente que el ambiente de la convivencia facilite a los seminaristas el misterio de su configuración con Cristo Sacerdote mediante el cultivo de la vida de fe. Para ello debe mantener un clima suficiente de oración y reflexión, de paz y de sosiego, de fraternidad y de respeto, que permita crecer en el conocimiento interno del Señor. El Seminario (...) antes que ser un lugar o un espacio material, debe ser un ambiente espiritual, un itinerario de vida, una atmósfera que favorezca y asegure un proceso formativo, de manera que el que ha sido llamado por Dios al sacerdocio pueda llegar a ser, con el sacramento del Orden, una imagen viva de Jesucristo..., dice PDV, 42 c.

\section{$2^{\mathrm{a}}$ Nota.- Subió al monte y llamó a los que él quiso; y vinieron junto a Él (Mc 3,13). El Seminario, una experiencia original de la vida de la Iglesia}

Siendo verdad que es obra de la Santa Trinidad de Dios el engendrar y configurar a los seminaristas con Cristo Sacerdote, esta obra de Dios se realiza ordinariamente a través de la mediación pedagógica establecida al efecto. En este caso, el Seminario como la comunidad promovida por el Obispo... Más adelante se especifica que el Seminario es, en sí mismo, una experiencia original de la vida de la Iglesia (PDV 60 d). Sin duda, su originalidad radica, entre otras notas, en su fin específico: el acompañamiento vocacional de los futuros sacerdotes, y por tanto el dis-

4 Los sacerdotes realizamos la vocación a la santidad en el seguimiento apostólico y sacerdotal de Cristo. Es nuestro peculiar camino de santificación personal, cuyo cultivo el Papa Juan Pablo II proponía como una prioridad pastoral de todo cristiano: Todos los cristianos, de cualquier clase y condición, están llamados a la plenitud de la vida cristiana y a la perfección del amor (Juan Pablo II, Carta Apostólica "Novo millennio ineunte", $\mathrm{n}^{\circ} 30$ ). También para el futuro sacerdote es una prioridad de la formación sacerdotal: un don a recibir del Espíritu del Señor y una tarea a realizar tanto personal como comunitariamente.

5 Benedicto XVI, Homilía en la Catedral de Sydney a sacerdotes y seminaristas, 19 de Julio de 2008. 


\section{COMUNICACIÓN \\ Seminario Mayor, una comunidad eclesial educativa}

cernimiento de la vocación, la ayuda para corresponder a ella y la preparación para recibir el sacramento del Orden (PDV 61 a). El Seminario tiene, pues, una encomienda específica y una responsabilidad intransferible.

Ya quedaron lejos los tiempos en que el Seminario, aislado del mundo exterior, realizaba su vida y misión de forma autosuficiente. Como toda comunidad eclesial, debe organizarse en el marco de la sociedad y de la Iglesia diocesana, abierto a ellas solidaria y servicialmente, (...) estando muy atento a sus necesidades (PFS 11), siempre desde su propia idiosincrasia. PDV reconoce la pluralidad de personas e instituciones que hoy pueden intervenir en la formación de los futuros sacerdotes 6 : además del Obispo con el equipo de formadores, inciden los profesores, la familia, la comunidad parroquial, los saerdotes, el grupo cristiano o el movimiento de procedencia... Todas ellas con los mejores deseos de colaborar en la obra buena que Dios ha iniciado en la biografía de de los seminaristas; a veces, por exceso de celo o por buscar los propios intereses, con intervenciones indebidas.

En efecto, el Seminario - y en su seno, el Obispo con el equipo de formadores - ejerce una solicitud peculiar sobre los futuros sacerdotes, derivada de la misión que a él, y solo a él, la Iglesia le encomienda: discernir, acompañar y formar los procesos vocacionales, para presentarlos al Obispo con vistas a la ordenación 7 . En esta alta y delicada misión el Seminario no puede dimitir, ni debe situarse en competencia con otras agrupaciones eclesiales: tiene su propia misión.

El Seminario debe valorar y respetar los variados y legítimos caminos espirituales a través de los cuales los seminaristas han escuchado la voz del Señor al seguimiento apostólico. Y agradecer cordialmente cuantas ayudas - materiales, intelectuales y espirituales - recibe de las familias, las parroquias, los movimientos o asociaciones en beneficio de los seminaristas, que pueden suponer un enriquecimiento y apoyo complementario para la formación. Pero es solamente responsabilidad del Seminario aplicando los criterios que la Iglesia tiene establecidos bajo la autoridad del Obispo - discernir la vocación y acompañar y cuidar de su crecimiento; educar en la identidad sustantiva y en la espiritualidad propia de los presbíteros diocesanos, y discernir y dar cohesión a las aportaciones que puedan provenir desde otro tipo de espiritualidades ${ }^{8}$. Suelo decir al respecto que nadie mejor que el Seminario puede aplicarse, análogamente,

6 Cf. PDV, 65-67

7 Cf. PFS 13, 16

8 PFS 65; Cf. PDV 68 
estas palabras de Pablo: Aunque hayáis tenido diez mil pedagogos en Cristo, no tenéis muchos padres. He sido yo quien, por el Evangelio, os engendré en Cristo Jesús (1Cor 4,15). Y ante la pluralidad de instancias que inciden en la formación sacerdotal, hacerlas respetar.

\section{$3^{\text {a }}$ Nota.- Jesús tomó aparte a los Doce, y les dijo por el cami- no: 'Mirad que subimos a Jerusalén,...' (Mt 20,17). EI Seminario, una comunidad en camino}

Dice PDV, y así lo recoge el vigente Plan de Formación Sacerdotal que el Seminario es sobre todo una comunidad educativa en camino ${ }^{9}$, aún cuando esté ubicado en un edificio concreto y su tarea educativa se extienda a lo largo de varios años. Ciertamente, esta imagen, dinámica y sugerente, hace referencia, en primer lugar, a la primera comunidad de los Doce discípulos en el seguimiento del Señor, aprendiendo de Él, convirtiéndose a Él, y disponiéndose a recibir en Pentecostés la nueva identidad apostólica. De manera análoga, aunque el Seminario es transitorio en el tiempo, en él se ponen las bases para la ordenación presbiteral que supone un cambio cualitativo en la identidad cristiana: de fiel laico pasar a ser sacerdote de Jesucristo por la gracia del sacramento del Orden.

La imagen del camino evoca, asimismo, el itinerario educativo que todos los candidatos al sacerdocio deben recorrer desde su entrada al Seminario hasta el día de su ordenación ${ }^{10}$. Esta perspectiva supone estructurar la formación en un proceso con etapas diferenciadas ${ }^{11}$, cada una con sus objetivos, contenidos y medios educativos bien precisados y diferenciados. Un proceso que se caracterice tanto por ser orgánico-unitario, como por su sintonía o correspondencia con el único fin que justifica la existencia del Seminario: la preparación de los futuros presbíteros (PDV, $61 \mathrm{c}$ ), de manera que los seminaristas vayan creciendo y madurando progresiva y simultáneamente en los diversos aspectos necesarios para la futura vida sacerdotal. Un itinerario común para todos y con el mismo nivel de exigencia, aún cuando siempre haya que tener en cuenta eventuales circunstancias personales en atención al viandante que dice PDV, 61 e.

9 CF. PDV, 60 b; PFS, 9

10 Cf. PFS 170

11 El Plan de Formación Sacerdotal de la C. E. E, contempla la organización del proceso educativo en una etapa preparatoria (Cf. PFS 184-189) y tres etapas de formación (Cf. PFS 190-222). 


\section{COMUNICACIÓN \\ Seminario Mayor, una comunidad eclesial educativa}

En efecto, no siempre el crecimiento de los seminaristas del mismo curso en las diferentes dimensiones de la formación es progresivo y simultáneo, más aún, si tenemos en cuenta la variedad de edades, procedencias y biografías de los actuales candidatos. En algunas ocasiones no es difícil encontrar desajustes, por ejemplo, entre la finalización del ciclo de estudios filosófico-teológico y la maduración suficiente en los restantes aspectos de la formación. Cabe la aparición de indecisión vocacional o signos de inmadurez afectiva estando ya avanzado el proceso educativo. Por ello considero necesaria la labor de artesanía pedagógica - sabia elasticidad dice PDV, 61 e - que acierte a conjugar la objetividad del proceso educativo en etapas con la persona de cada seminarista, contemplado en su misterio de dignidad, libertad y responsabilidad (PFS 173) en el momento y situación concretos de su formación. PDV insiste en que la labor educativa debe saber conciliar armónicamente la propuesta clara de la meta que se quiere alcanzar, la exigencia de caminar con seriedad hacia ella, la atención al 'viandante', es decir al sujeto concreto empeñado en esta aventura y, consiguientemente, a una serie de situaciones, problemas, dificultades, ritmos diversos de andadura y de crecimiento (PDV 61 e).

Si la acción educativa debe ser personalizada, cada seminarista tiene un camino propio que recorrer. El Seminario, como comunidad educativa en camino, es también el proceso o el camino interior que debe realizar cada candidato en el común marco educativo, desde que manifiesta deseos de ser sacerdote o dice sentirse llamado hasta que es capaz de decir al Señor ¡Aquí estoy, Señor, para hacer tu voluntad! con una conciencia lúcida sobre sí mismo y una libertad suficientemente purificada de falsas motivaciones, y dispuesta a ser vivida en la oblación de la caridad pastoral. Se trata de un proceso de peregrinación hacia el misterio que cada uno es para sí mismo, en el que no puede faltar el ahondar en la propia biografía personal, sus valores y sus defectos, sus deseos y frustraciones, los logros y las heridas que el pecado y los distintos avatares de la vida anterior han podido grabar en el corazón. Una peregrinación que no por ser personal deja de necesitar el acompañamiento solícito, lleno de afecto, de paciencia y de respeto, del formador y del director espiritual, y en algún caso, de la ayuda psicológica. Una peregrinación que, estimulada por la vocación sacerdotal, permita al futuro sacerdote encontrarse en el fondo del corazón con la presencia del amor de Cristo, y sabiéndose amado, reconocerse en este amor, sanar las heridas, asumir las eventuales debilidades, y recuperar la propia historia como una historia de salvación suscitada por el designio de Dios, hasta poder decir con S. Pablo: Por la gracia de Dios soy lo que soy, y la gracia de Dios no ha sido estéril en mí (1Cor 15, 10). 
Por fin, la definición del Seminario como comunidad educativa en camino alude también a la misma identidad evolutiva del Seminario: es verdad que, en todo tiempo, su identidad y finalidad es y será la de formar pastores según el corazón de Cristo Sacerdote. Pero como dice PDV 60, esta identidad constituye el ideal formativo que (...) estimula al Seminario a encontrar su realización concreta, fiel a los valores evangélicos en los que se inspira y capaz de responder a las situaciones y necesidades de los tiempos. Es decir, también el Seminario es una comunidad educativa en camino porque está llamado a evolucionar en sus formas de organización y en sus planes pedagógicos en relación con los cambios sociales y eclesiales, manteniendo siempre su fidelidad a la alta tarea que la Iglesia le tiene encomendada. Lejos de esclerotizarse, debe permanecer abierto a la corrección y a las nuevas perspectivas y planteamientos que imponen las orientaciones de la Iglesia y del propio Obispo, la experiencia y la evaluación del proyecto educativo y las características de las sucesivas generaciones de los seminaristas. El Seminario, por tanto, siendo fiel a la Iglesia y a sí mismo, ha cambiado con el transcurso del tiempo y deberá seguir cambiando en el futuro.

$4^{\mathrm{a}}$ Nota.- Los apóstoles se reunieron con Jesús y le contaron todo lo que habían hecho y lo que habían enseñado... (Mt $6,30)$. El Seminario, una fraternidad en torno a Jesús

La promulgación del decreto Optatam totius del Concilio Vaticano II ha impulsado no pocos dinamismos dirigidos a la renovación de la formación sacerdotal ${ }^{12}$. Me atrevería a señalar, entre los más importantes, el referente a la formación comunitaria: en la medida en que se ponía en relación con la teología conciliar del ministerio ordenado, la importancia de la formación comunitaria iba creciendo hasta llegar a convertirse en una dimensión de la formación sacerdotal que debe cualificar y traspasar todo proyecto educativo como ámbito normal del crecimiento de los futuros presbíteros. No en vano, como recordábamos antes, PDV contempla el Seminario como una continuación en la Iglesia, de la íntima comunidad apostólica formada en torno a Jesús, y afirma de los seminaristas que

12 Cf. PFS 145-169. Tanto en el vigente Plan de Formación para el Ministerio Presbiteral de la C. E. E. de 1996, como el inmediatamente anterior de 1986, coinciden en considerar la formación comunitaria como una dimensión formativa para el futuro sacerdote tan sustantiva como la humana, la espiritual, la intelectual y la pastoral. Todas ellas han de estar simultáneamente presentes en el proceso y, sobre la base de la formación espiritual, guardan entre sí una perfecta armonía y unidad pedagógica (PFS 47). 


\section{COMUNICACIÓN \\ El Seminario Mayor, una comunidad eclesial educativa}

reunidos por el Espíritu en una sola fraternidad, colaboran, cada uno según su propio don, al crecimiento de todos en la fe y en la caridad, para que se preparen adecuadamente al sacerdocio (PDV $60 \mathrm{~d}$ ).

Se trata de recrear durante el tiempo del Seminario la experiencia de fraternidad que el Señor construyó con los Doce para hacer de los seminaristas una comunidad apostólica, con la mirada puesta en el mañana del presbiterio diocesano. Íntima fraternidad sacramental lo llama el Concilio Vaticano II ${ }^{13}$, y el Papa Juan Pablo II afirma al respecto que el ministerio ordenado tiene una radical 'forma comunitaria' y puede ser ejercido sólo como una tarea colectiva (PDV 17 a). Para educar esta dimensión esencial del sacerdote está el recorrido formativo que se realiza en el Seminario. En cierto modo, cuando Jesús llama a los Doce y los pone a su lado para que estén con Él y para enviarlos a predicar (Mc 3, 14). inicia con ellos una especie de seminario14: les introduce en los misterios del Reino, les enseña, les corrige, se sienta con ellos en la cena eucarística, les hace testigos de su Pascua, etc., para hacer de cada discípulo un apóstol, y de todos, una fraternidad: Pedro y los Once, paradigma de toda fraternidad sacramental.

La relación con la Iglesia ${ }^{15}$, sustantiva del ministerio sacerdotal, postula igualmente subrayar la formación en régimen de vida comunitaria. La comunidad del Seminario es el medio adecuado para el crecimiento y la maduración de los seminaristas, constituyendo, en este sentido, una verdadera experiencia eclesial ${ }^{16}$, que permite educar las disposiciones indispensables para quien está llamado a ser servidor de la Iglesia comunión, porque -unido al Obispo y en estrecha relación con el presbiterio- construye la unidad de la comunidad eclesial en la armonía de las diversas vocaciones, carismas y servicios (PDV 16 e). Además, como se ha señalado acertadamente, las relaciones fraternales entre los miembros de la comunidad educativa ayudan a la maduración de la afectividad y de la capacidad de relación con los demás, fundamental para quien deberá

${ }^{13}$ Concilio Vaticano II, PO 8: Presbyteri, per Ordinationem in Ordine presbyteratus constituti, omnes inter se intima fraternitate sacramentali nectuntur... 14 Cf. Congregación para la Educación Católica, Directrices sobre la preparación de los formadores en los seminarios, Roma 1993, nº 17.

15 Cf. PDV 16-18

16 En efecto: en la comunidad del Seminario se cultiva la llamada del Señor; se conoce y profundiza el misterio de Cristo; se aprende a vivir en el estilo Evangelio, y cada día se experimenta la fraternidad como amor hecho servicio. 
ejercer su ministerio en medio del mundo como el hombre de la misión y del diálogo 17.

La oportunidad del número y la prudencia pedagógica pueden aconsejar establecer en el seno de la comunidad del Seminario, comunidades o grupos más reducidos de seminaristas, agrupados según su nivel de formación. Así, el Seminario de Madrid, se organiza como una comunidad de comunidades, en la que, sin menoscabo de la unidad de formación de todo el conjunto, resulta más fácil la gradualidad de la formación, evitando el peligro siempre latente de colectivismo. La experiencia ha sancionado la bondad de esta fórmula que posibilita una comunicación más fluida y amistosa entre todos los miembros - también entre los de distintas comunidades - y la participación corresponsable en las diversas tareas del Seminario. Sobre todo, esta fórmula favorece el que cada seminarista pueda sentirse protagonista necesario e insustituible de su formación (PDV 69), condición indispensable para que se viva en el Seminario no de un modo extrínseco y superficial, como si fuera un simple lugar de habitación y de estudio, sino de un modo interior y profundo (PDV 60 f) como una verdadera experiencia espiritual análoga a la de los Doce con Jesucristo.

Al Seminario, como a la fraternidad apostólica, ninguno se incorpora por propia voluntad si no es previamente llamado por el Señor. Ninguno elige al compañero por simpatía, proximidad ideológica o afinidad espiritual sino que todos se encuentran en el Señor que llamó a los que quiso para que estuvieran con Él (Mc 3, 13 ss). Cada discípulo es llamado en su personalidad original e irrepetible a entrar en comunión de vida con Cristo, y en esta comunión con Él, recibe el don de la fraternidad entre todos. La comunidad educativa en el Seminario sólo se explica, en último término, desde el amor y la gratuidad de Dios y encuentra su razón de ser, su sentido, su estilo y su modo de vida en la persona de Jesucristo Siervo y Pastor. Acoger el regalo de la comunidad como don de Dios, supone vivir esta experiencia con gratitud, confianza y solidaridad; extremando la amabilidad y el espíritu de servicio; sin miedo a compartir la propia verdad, dejándose educar por la palabra, el gesto y el afecto de los otros. La vida comunitaria es el lugar donde se descubre la herida profunda del propio ser y donde se aprende a asumirla. Entonces se puede empezar a renacer, decía, con belleza y razón, un profesor y pensador cristiano ${ }^{18}$. Cuando en las relaciones comunitarias la centralidad de Cristo se oscurece o se olvida, en ellas no está el Espíritu del Señor. Se rompe la ecle-

17 PDV 18 b. Cf. igualmente PDV 43 d; PFS 58, 59,88.

18 Cf. Carlos Díaz, Carta a mis hijos, en Alfa y Omega, 286, pg. 3 


\section{COMUNICACIÓN \\ Seminario Mayor, una comunidad eclesial educativa}

sialidad y brota el conflicto de los intereses particulares. Las diferentes edades, biografías, procedencias, sensibilidades de los miembros de la comunidad educativa no dejan de presentar, en este sentido, un reto permanente a la comunión. No es el único: el individualismo exacerbado que culturalmente se respira puede contaminar el estilo cristiano de la comunidad. No hay que asustarse. También los Doce tuvieron sus pecados, vacilaciones y conflictos: les costó acostumbrarse a vivir como hermanos. Pero aprendieron del Señor a vivir para los demás y con los demás; tuvieron que arrepentirse de sus egoísmos, intolerancias, vanidades y frivolidades, y acabaron siendo los ministros de la comunión en Cristo, en la predicación apostólica y en la Eucaristía.

La fraternidad del Seminario, al tener su fundamento en Cristo, debe nutrir y renovar cada día su identidad y su sentido en la escucha común de la Palabra de Dios, en la oración personal y litúrgica, y, sobre todo, en la Eucaristía que edifica la comunidad educativa como Cuerpo de Cristo: Porque uno solo es el pan, aun siendo muchos, un solo cuerpo somos, pues todos participamos del mismo pan (1Cor 10, 16). En coherencia con esta nueva vida en Cristo, brota un nuevo corazón, un nuevo lenguaje y una nueva forma de actuar; se visibiliza la verdadera identidad del Seminario y se propone una forma, también nueva, de vivir las relaciones con Dios y entre los hermanos. Formas de relación ciertamente contraculturales, porque se derivan de pensar como Cristo, sentir como Cristo y actuar como Cristo. Si lo habéis recibido dignamente, vosotros sois eso mismo que habéis recibido, decía San Agustín ${ }^{19}$ refiriéndose a la comunión eucarística. Por eso la Eucaristía es el momento esencial de la jornada (PDV 48 c) del Seminario que, en el día a día de la celebración, debe ir adquiriendo fisonomía y estilo eucarísticos en todos y en cada uno de sus miembros.

La forma eucarística de la existencia cristiana se manifiesta de modo particular en el estado de vida sacerdotal afirmaba el papa Benedicto XVI20 recientemente. En consecuencia, vivir con estilo eucarístico la vida del Seminario es crecer en aquello que se celebra y se recibe: la fraternidad en Cristo, que precede y se da como un regalo; que cada día se renueva y alimenta en la Eucaristía. Pero, sobre todo, se trata de una comunión intensa y profunda con la misma caridad pastoral de Cristo, en donde el futuro sacerdote aprende la donación de sí, la total donación de sí a la Iglesia, compartiendo el don de Cristo y a su imagen (PDV 23 b). Dicho de otra forma, la entrega sacerdotal de la vida, dejándose educar en la expropiación de uno mismo, en la renuncia y en el sacrificio; y haciendo

19 San Agustín, Sermón 227, 1

20 Sacramentum caritatis, 2007, $\mathrm{n}^{\circ} 80$ 
de la caridad pastoral que mana de la Eucaristía el principio interior y dinámico (PDV $23 \mathrm{~g}$ ), la clave en torno a la cual se van unificando todas las dimensiones y tareas de la formación sacerdotal. Por eso las palabras de la consagración esto es mi cuerpo que será entregado por vosotros deben hacerse estilo de vida y compromiso personal del futuro sacerdote, aprendiendo a decir con el Señor: Aquí está mi cuerpo, es decir, toda mi persona y mi vida, porque yo como futuro sacerdote quiero entregarme por todos contigo y por ti.

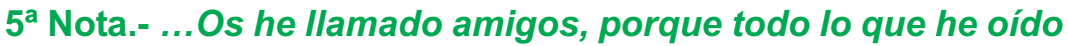
a mi Padre os lo he dado a conocer (Jn 15,15). La relación educativa en el Seminario

Formadores y seminaristas integran una misma y única comunidad y las relaciones entre unos y otros han de ser las que corresponden a una comunidad cristiana (PFS, 256). Compartiendo los mismos objetivos, se trata de ir haciendo crecer en los seminaristas su configuración vital con Cristo, Apóstol y sumo Sacerdote de nuestra fe (Heb 3,1), aprendiendo de su entrega en obediencia perfecta al Padre y en profunda solidaridad con todo lo humano, menos con el pecado: la mediación sacerdotal única y perfecta que permanece para siempre, e inaugura el verdadero culto existencial agradable a Dios. La muerte de Cristo, transformada en su corazón en ofrecimiento de amor extremo - amor filial al Padre, amor fraterno hacia los hombres - es el único sacrificio plenamente digno de $\operatorname{Dios}^{21}$. No fue un camino fácil para el Señor que aunque era Hijo, aprendió sufriendo lo que cuesta obedecer (Heb 5, 8).

En definitiva se trata de ir educando en el existir in forma Christi como imperativo para quien está llamado a actuar sacramentalmente in persona Christi: entregar la vida por amor en obediencia al designio salvador del Padre, médula de la identidad sacerdotal. Como es obvio, éste es el aspecto central de toda la formación, y reclama la identificación progresiva, total e incondicional del futuro sacerdote. Cuando el Señor llama al sacerdocio apostólico, no reclama sólo una parte de la vida, o del tiempo, o de las cosas que se poseen; pide la entrega total de la persona y para siempre, pasando a ser de su propiedad y compartiendo con Él vida, misión y destino. Ser encontrado por Cristo supone relativizarlo todo, estar dispuesto a perderlo todo con tal de seguirle a Él. El signo y la prueba más elocuente de la veracidad de la llamada y de la calidad de la

21 Cf. A. Vanhoye, La sacramentalidad del ministerio, Espiritualidad del presbítero diocesano secular, Symposio, Madrid, 1987, p. 73 ss 


\section{COMUNICACIÓN \\ Seminario Mayor, una comunidad eclesial educativa}

resuesta del futuro sacerdote está en mostrar la misma disposición de Pablo a dejar o perder todo por Cristo: juzgo que todo es pérdida ante la sublimidad del conocimiento de Cristo Jesús, mi Señor, por quien perdí todas las cosas, y las tengo por basura para ganar a Cristo,... (Flp 3, 8).

Los formadores profundamente unidos al Obispo, al que, con diverso título y de modo distinto representan... (PDV 66 a) ejerciendo la autoridad educativa acompañan y posibilitan este diálogo de gracia, contando con la libertad responsable de los seminaristas ${ }^{22}$. Considero irrenunciable en las actuales circunstancias la educación en esta libertad cristiana, so pena de caer en un autoritarismo estéril que puede generar doblez de vida en los formandos. Con todas las dificultades y problemas, aún a riesgo de ingenuidad, no se puede ni se debe dimitir de educar a los seminaristas en y para la libertad, vivida cristiana y sacerdotalmente. Una libertad que se hace oblación por amor en obediencia al Señor y a su Iglesia y en servicio a los hermanos ${ }^{23}$. Una libertad que, redimida por la gracia de Cristo, pone en evidencia el pecado personal y se hace camino de conversión permanente. Los futuros presbíteros deben experimentar que cuando entregan a Dios su libertad -la libertad del siervo- Él la devuelve plenificada al ciento por uno -la libertad del hijo- en la nueva forma de vida sacerdotal del Hijo entregado.

Los diversos problemas planteados en la relación autoridad educativa libertad con los jóvenes seminaristas nos plantean la necesidad de clarificar el contenido específico de esta autoridad y el modo de ejercerla, desde una cada vez más íntima convicción: del ejercicio decidido y razonable de la autoridad educativa depende, en gran manera, la incidencia del Seminario en los seminaristas y la calidad cristiana y formativa de la comunidad educativa.

En primer lugar, los problemas derivados de la cultura dominante. El Papa, en PDV, nos hace caer en la cuenta de que nuestros seminaristas, como hijos de su tiempo, participan de una concepción de la libertad no cristiana, vivida como un fin en sí misma, proclive al individualismo: Hay

22 Cf. PDV 69; PFS 54, 57, 60, 162, etc.

23 PDV 36 cita, a propósito de la libertad como oblación, esta bella reflexión del Papa Pablo VI: A la llamada -decía Pablo VI- corresponde la respuesta. No puede haber vocaciones, si no son libres, es decir, si no son ofrendas espontáneas de sí mismo, conscientes, generosas, totales... Oblaciones; éste es prácticamente el verdadero problema... Es la voz humilde y penetrante de Cristo, que dice, hoy como ayer y más que ayer: ven. La libertad se sitúa en su raíz más profunda: la oblación, la generosidad y el sacrificio. 
que constatar también una defensa exacerbada de la subjetividad de la persona, que tiende a encerrarla en el individualismo... (PDV $7 \mathrm{c}$ ). ¡Cuántas veces el me apetece, el es que tengo derecho a..., y otras expresiones similares se erigen como criterio de razón y de comportamiento en la vida del Seminario!

Además, la sensibilidad cultural dominante que no acepta más autoridad que aquella que es democráticamente elegida o consensuada. Pero, en nuestro caso, los seminaristas no eligen a sus formadores; los reciben como un elemento institucional del Seminario con los que han de establecer una relación educativa en profundidad, y -salvando el fuero internono limitada solamente a los aspectos disciplinares. Si esta mentalidad democratizadora se transfiere al Seminario, no es posible más autoridad que aquella que es previamente elegida o aceptada por su carisma personal. No cabe entonces, de facto, ni la autoridad legitimada por la ordenación y la misión recibida de Cristo $24 \mathrm{ni}$, correlativamente, el ejercicio evangélico de la obediencia. ¡Cuántas veces el complejo de ser tachados de autoritarios o de poco dialogantes nos ha inhibido de nuestra responsabilidad específica...!

La autoridad educativa de los formadores, recibida en la encomienda del Obispo, se funda en la autoridad pastoral derivada de la ordenación sacramental por la que el sacerdote se configura con Jesucristo, en cuanto Cabeza y Pastor de la Iglesia, y recibe como don una 'potestad espiritual', que es participación de la autoridad con la cual Jesucristo, mediante su Espíritu, guía la Iglesia (PDV 21 a), y participa de la caridad pastoral del Señor por el don del Espíritu Santo y la implicación responsable de toda su vida entregada. En el ejercicio ministerial se actualiza, pues, la autoridad y la caridad pastoral de Jesucristo, Cabeza y Pastor de la Iglesia. Con la missio recibida del Obispo para ser formador, se actualiza esta autoridad pastoral para el ámbito del Seminario y, en correlación con su finalidad, se cualifica como autoridad educativa.

Obviamente los formadores están reclamados a vincular en su existencia sacerdotal el don de la autoridad ministerial con la exigencia de crecer en autoridad moral y en preparación pedagógica, según los criterios que la Iglesia reclama para los tiempos actuales. La potestas sacramental necesita ir acompañada de la autoridad moral y de una básica competencia educativa. La tarea formativa debe transparentar la imagen del Buen Pastor; ser servicial, sencilla y generosa en sus manifestaciones y en sus gestos; cercana y dialogante con los educandos; estimulante y animadora de sus potencialidades... Es el contenido propio de la forma gregis, de

24 Cf. G. Greshake, "Ser Sacerdote”, Salamanca, 1995, p. 19 ss 
ser el modelo del rebaño (cf. 1Pe 5,3) mediante una vida sacerdotal que se ofrece en debilidad y búsqueda de santidad como tipo, ejemplo, y testimonio de la comunidad educativa objeto de su solicitud.

De la correcta asunción de esta potestad espiritual, se derivan consecuencias importantes, tanto para los formadores como para los seminaristas. Los sacerdotes-formadores no podemos olvidar que toda acción pastoral, también la educativa, está siempre remitida y subordinada a Jesucristo Cabeza y Pastor -en cuya persona actuamos-e inserta en el don del Espíritu Santo que es quien da la luz, la sabiduría y la gracia, y transforma la vida del Seminario en un verdadero proceso iniciático, en una catequesis mistagógica, como decíamos antes: No hay, por tanto, auténtica labor formativa para el sacerdocio sin el influjo del Espíritu de Cristo (PDV 65 c). Las vocaciones al sacerdocio no son propiedad del equipo de formadores, ni éste tiene derecho a educarlas y discernirlas con criterios que no sean estrictamente eclesiales. Tampoco a formarlas a su imagen y semejanza, sino a imagen y semejanza de Cristo, el Buen Pastor. Respetando siempre la indisponible acción del Espíritu en cada obra original y única que es un futuro sacerdote.

También para los seminaristas tiene importantes consecuencias fomentar su educación en régimen de libertad responsable, afirma: En este proceso educativo hacia una madura libertad responsable puede ser de gran ayuda la vida comunitaria del Seminario (PDV 44 f), y ayudarles a situarla oblativamente -como obediencia por amor- en su relación con la autoridad educativa. Deben crecer en el convencimiento de que su futuro sacerdotal exige una formación clara y sólida para una libertad, que se presenta como obediencia convencida y cordial a la "verdad» del propio ser, al significado de la propia existencia, o sea, al 'don sincero de sí mismo', como camino y contenido fundamental de la auténtica realización personal (PDV ibid.). En el Seminario no cabe, pues, una relación verdaderamente educativa que no se sitúe en el horizonte espiritual de la obediencia de la fe. Los seminaristas deben experimentar que la autoridad en la Iglesia es objeto de fe, y que a quien se obedece por esta mediación es a Jesucristo. No es la afinidad ideológica o espiritual, ni la simpatía personal, ni la admiración a un liderazgo humanamente brillante lo que funda la obediencia. Es el principio ministerial de la representatio Christi -el carácter sacramental del ministerio- el que, fundamentando la autoridad educativa, permite ejercerla y reclamar la oblación responsable de la libertad del formando25.

25 Considero que en esta aceptación de la autoridad objetiva en la obediencia de la fe se juegan aspectos importantes de la identidad sacerdotal. Con 
$6^{a}$ Nota.- Llama a los Doce y comenzó a enviarlos de dos en dos, dándoles autoridad,... (Mc 6, 7). El Seminario, fraternidad para la misión

Afirmábamos que el Seminario no debe ser una comunidad autosuficiente y cerrada sobre sí misma. Como comunidad eclesial diocesana, el Seminario vive en comunión con su Obispo y su Presbiterio, conoce de cerca sus preocupaciones pastorales y está inserto en la vida de la Diócesis participando de sus esperanzas e inquietudes y prestando, dentro de sus posibilidades, aquellos servicios que el Seminario puede ofrecer a la comunidad diocesana (PFS 12). La condición misma de presbítero diocesano secular aconseja que la formación no se realice al margen de las realidades que los seminaristas, una vez ordenados, servirán como pastores. Puesto que toda la formación del Seminario se dirige a la formación de verdaderos pastores de las almas, a ejemplo de nuestro Señor Jesucristo, Maestro, Sacerdote y Pastor26 la comunidad educativa debe propiciar y estimular la dimensión pastoral de la formación con un conocimiento suficiente del mundo actual, sus cambios y acontecimientos más singulares, con capacidad de discernirlos e iluminarlos desde el Evangelio, leído en la tradición de la Iglesia27. A ello deben contribuir entre otros medios las experiencias apostólicas y pastorales organizadas en consonancia con el momento educativo de los seminaristas y articuladas con las demás dedicaciones del Seminario.

Desde la perspectiva de la comunidad educativa del Seminario, estos envíos son coyunturales, como lo fue el primer envío de los Doce en la vida histórica de Jesús (Cf. Mc 6, 2. 30). Hasta la ordenación sacerdotal se debe conjugar el tiempo fundamental de vida oculta que, por analogía, es el Seminario con estas actividades pastorales, que no por incipientes o fragmentarias dejan de reclamar la implicación del corazón y el deseo de servir al Señor en los hermanos. Su objetivo fundamental no es anticipar prematuramente el ejercicio del ministerio, sino crecer en una verdadera y propia iniciación a la sensibilidad del pastor (PDV 58 a) y en una

la ordenación sacramental, los futuros sacerdotes participarán en la autoridad salvadora de Cristo, vivida bajo la forma de siervo. Sin asumir con lucidez y humildad este principio no podrán comprenderse a sí mismos correctamente; juzgarán con intolerancia a su Obispo y a sus hermanos presbíteros, y tenderán a dominar clericalmente a los laicos.

26 Cf PDV 57 a; PFS 16

27 Cf. PDV 57 d; PFS 120 


\section{COMUNICACIÓN \\ El Seminario Mayor, una comunidad eclesial educativa}

comunión cada vez más profunda con la caridad pastoral de Jesús (PDV $57 \mathrm{f}$ ) mediante una presencia que comporta irradiar el testimonio de la vida cristiana y de la vocación sacerdotal, el aprendizaje de la escucha atenta y paciente de la realidad, y el servicio humilde y generoso de la propia vida.

Quisiera señalar algunos aspectos de la dimensión pastoral de la formación que, en estos momentos, me parecen más necesarios de ser cultivados con la mayor atención. Quieren responder a las dificultades que se perciben a la hora de incorporar a los nuevos presbíteros a la misión de la Iglesia. No pocas provienen de las circunstancias culturales y sociales, poco favorables para la evangelización y la vida de la Iglesia. No nos faltan ejemplos prácticos en nuestro alrededor que dan la razón a la tremenda afirmación de Juan Pablo II de que la cultura europea da la impresión de ser una apostasía silenciosa por parte del hombre autosuficiente que vive como si Dios no existiera28.

Los tiempos reclaman a todos los cristianos -también a los sacerdotes y a los que se preparan para serlo- acentuar el carácter martirial de la profesión de fe en el sentido etimológico de la palabra mártir; es decir, ser testigos sin fisuras y con todas las consecuencias de Jesucristo vivo y presente en su Iglesia. Ciertamente los seminaristas tienen que asumir vivir a contracorriente de los modos y maneras de este mundo, en una sana e incómoda disidencia social29. Pero, al mismo tiempo, hay que ayudarles a insertarse en esta sociedad con rigor y estilo misioneros, siem-

28 Juan Pablo II, Exhortación Apostólica "Ecclesia in Europa", 2003, n 10. En nuestro país estamos viviendo actualmente la versión española -condicionada por la propia historia del pasado siglo- del análisis más general que, con toda lucidez cristiana, Juan Pablo II nos ofrece en esta Exhortación Apostólica. Una sociedad, la europea, en la que parece haberse oscurecido la esperanza ( Cf. EE, 7). Dice el Papa que, en la raíz de este oscurecimiento, está el intento de hacer prevalecer una antropología sin Dios y sin Cristo. Esta forma de pensar ha llevado a considerar al hombre como el centro absoluto de la realidad, haciéndolo ocupar falsamente el lugar de Dios y olvidando que no es el hombre el que hace a Dios, sino que es Dios quien hace al Hombre (EE 9).

29 Es necesario, mirando a nuestros jóvenes seminaristas, recordarles las palabras de estímulo que el apóstol Pablo, bregado en las duras tareas apostólicas, dirige desde la cárcel a Timoteo, su joven sucesor en el ministerio apostólico; No te avergüences, pues, ni del testimonio que has de dar de nuestro Señor, ni de mí, su prisionero; sino al contrario, soporta conmigo los duros trabajos por el Evangelio, ayudado por la fuerza de Dios (2Tim 1,8 
pre desde la secularidad específica del sacerdote secular. Una inserción en este mundo sin complejos de inferioridad, sin petulancias, y sin fundamentalismos, frente a posibles visiones pesimistas, temerosas o excluyentes del tiempo presente; con la racionalidad crítica que brota del Evangelio y del Magisterio de la Iglesia. Una inserción que vaya madurando la caridad de Cristo en el futuro pastor que mira al mundo desde las entrañas de misericordia del Padre: Tanto amó Dios al mundo que entregó a su Hijo único, para que todo el que cree en Él no perezca, sino que tenga vida eterna. Dios no envió a su Hijo al mundo para condenarlo sino para salvarlo (Jn 3, 16-17). Una inserción que ve con realismo las dificultades presentes, y señala con claridad la injusticia y el pecado, poniendo en juego la pasión evangelizadora con la confianza puesta en el poder salvador del Señor y de su Espíritu.

No creo que se pueda sembrar una pasión evangelizadora en los futuros sacerdotes si no se les dota de una formación intelectual razonablemente anclada en la verdad de Dios y en la del hombre a la luz de Dios, sin equívocos ni confusiones ${ }^{30}$. Además, en las circunstancias actuales, asegurar la fidelidad perpetua a los compromisos sacerdotales resulta poco menos que imposible sin unas certezas teológicas básicas que broten de la contemplación del misterio de Cristo, y alimenten la vocación sacerdotal y el riesgo de dar la vida por el Evangelio. Siempre en la comunión de la Iglesia y con sus pastores, y en solidaridad con las pobrezas, sufrimientos y las búsquedas de sentido de sus hermanos los hombres.

La comunidad educativa del Seminario es el ámbito adecuado para cultivar el gusto por la tarea y la belleza del estudio, con vistas a ofrecer la razón de la propia fe en el momento presente, e iluminar con la luz del Evangelio los problemas sociales, antropológicos o científicos 31 : Si todo cristiano debe estar dispuesto a defender la fe y dar razón de la esperanza (...) mucho más los candidatos al sacerdocio y los presbiteros deben cuidar diligentemente el valor de la formación intelectual en la educación y en la actividad pastoral (PDV 51 b). Sin arrogancias, y en actitud dialogal -el hombre de la misión y del diálogo- (PDV 18 b) pero con la fortaleza de quien se siente servidor de la verdad de Cristo Salvador, que le precede, le sostiene, y le orienta en el camino del ministerio.

\section{Cf. PFS 106}

${ }^{31} \mathrm{El}$ ministerio de la palabra es sustantivo en el sacerdote. De ahí la necesidad imprescindible de capacitarles para predicar el Evangelio en relación con los problemas e interrogantes de la cultura actual; educar a los hermanos en la fe e iluminar cristianamente su vida personal, familiar, profesional y social. 
Resumiendo: el Seminario, como comunidad educativa de futuros pastores, no puede dejar la tarea de actualizar en los seminaristas los rasgos del Buen Pastor: hombres de su tiempo con sana y resistente humanidad; firmemente arraigados en Cristo, apasionados por la comunión en la Iglesia y entregados sin reservas a la misión; en obediencia, fidelidad y afecto a los pastores. Con una sólida preparación espiritual y académica para predicar el Evangelio y sembrar el amor y la esperanza; cercanos a los pobres y a los pecadores, y solidarios con los que trabajan por la paz y la justicia para que el hombre refleje la gloria de Dios.

Mirando a nuestros seminaristas -un bien eclesial por desgracia escasocreo poder afirmar que, en su conjunto, son humanamente valiosos, sanos cristianamente y leales en el deseo de consagrar su vida al servicio del Señor como pastores de su pueblo. Un verdadero milagro de Dios para los tiempos que corren. Sin embargo, en algunos círculos sacerdotales no deja todavía de manifestarse un cierto prejuicio generacional, un posicionamiento ideológico un tanto crítico hacia las jóvenes generaciones. Estoy seguro, sin embargo, de que las nuevas generaciones, con la gracia del Espíritu Santo, sabrán estar a la altura de los arduos trabajos por el Evangelio en el tiempo que les ha sido dado vivir, si aciertan a hablar el lenguaje del servicio abnegado que todo el mundo entiende: la disponibilidad para ser enviados donde la Iglesia lo necesite, sin eludir los destinos más pobres o más necesitados de la justicia y del consuelo de Dios. El lenguaje de una vida entregada al trabajo pastoral, sin medir tiempos, dedicaciones o beneficios; como verdaderos servidores del Señor y de sus hermanos, sin buscarse a sí mismos ni buscar la carrera eclesiástica. Hablando con sus hechos, en definitiva, el mismo lenguaje pastoral de Pablo: Por mi parte, muy gustosamente gastaré y me desgastaré por vuestras almas (2Cor 12, 15).

\section{CONCLUSIÓN: A MODO DE COMUNICACIÓN FRATERNA.}

El designio providencial del Señor ha querido vincular gran parte de mi ministerio a la tarea de la formación sacerdotal en el Seminario de Madrid. Son muchas las satisfacciones del servicio como Rector y no pocos los problemas y dificultades. En todo caso, lo considero un verdadero e inmerecido regalo de Dios, por el que le doy gracias cada día. Y no puedo dejar de confesar que, aún presidiendo la comunidad educativa, yo he sido su primer beneficiado en un proceso de maduración sacer- 
dotal nunca acabado y siempre abierto a nuevos aprendizajes. Porque sigue y seguirá estando de permanente actualidad la pregunta fundamental que provoca la bella y profunda reflexión de PDV: ¿Cómo formar sacerdotes que estén verdaderamente a la altura de estos tiempos, capaces de evangelizar al mundo de hoy? (PDV 10 a) Seguir buscando la respuesta es entregar la vida como testigo, formador y sacerdote.

Muchas gracias por su atención. 